\title{
SISTEM PENDUKUNG KEPUTUSAN PEMILIHAN “BEST AGENT" DENGAN METODE PROFILE MATCHING (GAP)
}

\author{
Brian Arif Maulana ${ }^{1}$, Agus Budiyantara ${ }^{2}$ \\ ${ }^{1,2}$ Pogram Studi Teknik Informatika, STMIK Widuri, Jakarta Indonesia \\ E-mail : ${ }^{1}$ brian.arif@gmail.com, ${ }^{2}$ agusbudiyantara@yahoo.co.id
}

\begin{abstract}
The problem of selecting the "Best Agent" is still done manually, by giving a value to the form that contains the assessment criteria and the sum of the values of each criterion that is averaged so that the final result is obtained. The purpose of this study is to discuss and build systems and models for making decisions to determine the "Best Agent" using the Profile Matching method. Application Decision Support System Selection "Best Agent" Profile Matching method an application designed to provide accurate decisions based on current data and can be accounted for, this is expected to improve the quality of staff and the expectations it builds to improve the quality of Human Resources.
\end{abstract}

Keywords: Staff, Change Agent, Best Agent, Profile Matching

\begin{abstract}
ABSTRAK
Permasalah Pemilihan "Best Agent" masih dilakukan secara manual, dengan memberikan nilai pada form yang berisi kriteria penialain dan hasilnya adalah penjumlahan nilai dari tiap kriteria yang dirata-rata sehingga memperoleh hasil akhir. Tujuan penelitian ini adalah untuk merancang dan membangun sebuah sistem dan model dalam pengambilan keputusan untuk menentukan "Best Agent" menggunakan metode Profile Matching. Aplikasi Sistem Pendukung Keputusan Pemilihan "Best Agent" metode Profile Matching merupakan sebuah aplikasi yang dirancang untuk memberikan sebuah alternatif keputusan yang akurat didasarkan pada data terkini dan dapat dipertanggungjawabkan, hal ini diharapkan dapat meningkatkan kualitas kinerja staff dan harapan besarnya adalah terbangunnya peningkatan kinerja yang baik sehingga meningkatkan kualitas Sumber Daya Manusia.
\end{abstract}

Kata kunci: Staff, Change Agent, Best Agent, Profile Matching.

\section{PENDAHULUAN}

Departemen Statistik Bank Indonesia setiap tahun melakukan evaluasi kinerja dengan menggelar sebuah acara yang diberi nama "Change Agent" dan untuk karyawan yang berprestasi diberi nama "Best Agent" dan dalam proses ini dilakukan oleh Divisi Satuan Layanan Administrasi (SLA) dan dengan bantuan data dari Departemen Sumber Daya Manusia (Yudi Agusta, 2007). Dalam penentuan "Best Agent" ini berdasarkan penilaian kinerja, yaitu persentase absen, keahlian, komunikasi dan kerjasama, dan fleksibilitas. Agenda rutin khusus Departemen Statistik yang dilakukan setiap akhir tahun terlepas dari agenda tahunan Bank Indonesia mengenai penilaian karyawan. Maksud "Best Agent" disini adalah level staff kebawah, dilihat dari grade jabatan adalah grade 1 sampai dengan grade 3 yaitu dari asisten pelaksana hingga asisten manager. Dalam mengambil keputusan terhadap pemilihan "Best Agent" masih diproses secara manual yaitu dengan memberikan nilai pada form tiap kriteria dan hasilnya adalah rata-rata dari penjumlahan nilai dari tiap kriteria tersebut. Dengan adanya sistem tersebut pemberi nilai (manager) sulit menentukan dan memakan waktu proses yang lama sehingga kurang efisien.

Profile Matching adalah sebuah mekanisme pengambilan keputusan dengan mengansumsikan bahwa terdapat tingkat variabel prediktor yang ideal yang harus dimiliki oleh pelamar, bukannya tingkat minimal yang harus dipenuhi atau dilewati (Sitanggang \& Sibagariang, 2019).

Tujuan penelitian ini adalah untuk merancang dan membangun sebuah sistem dan model dalam 
pengambilan keputusan untuk menentukan "Best Agent" menggunakan metode Profile Matching (Sani, 2016). Untuk mengatasi permasalahan di atas, maka perlu dibangun suatu sistem pendukung keputusan dengan menerapkan suatu metode perangkingan yaitu dengan menggunakan metode Profile Matching (Setiawan et al., 2017). Dengan metode tersebut diharapkan kedepannya dapat memberikan kemudahan dalam sebuah sistem yang berjalan dan lebih memberikan manfaat serta efisiensi waktu bagi manager dalam mengolah data yang ada dalam pemilihan "Best Agent" dalam acara rutin tahunan yang diberi nama "Change Agent" di Departemen Statistik Bank Indonesia (Apriana, 2019).

\section{METODE PENELITIAN}

Metode penelitian merupakan cara ilmiah untuk mendapatkan data dengan tujuan dan kegunaan tertentu. Sedangkan teknik pengumpulan data menurut (Sugiyono, 2013) teknik pengumpulan data merupakan langkah yang paling strategis dalam penelitian, karena tujuan utama penelitian dalah mengumpulkan data. Metode yang digunakan penulis adalah sebagai berikut :

Metode pengumpulan data meliputi:

1. Studi Literatur

Dilakukan dengan cara mencari dan mempelajari referensi yang behubungan dengan kegiatan penelitian yang dilakukan.

2. Pengamatan / Observasi Melakukan kegiatan pengamatan dan analisa terhadap alat penunjang yang digunakan pada kegiatan penelitian.

3. Wawancara Mengadakan konsultasi dengan narasumber di kantor yang berhubungan dengan permasalahan yang dihadapi selama penelitian.

Metode perancangan yang digunakan penulis adalah SDLC (Systems Development Life Cycle) model Waterfall, dimana konsep awal adalah mencari kebutuhan user, kemudian penulis analisa system terebut, selanjutnya adalah mendesain kebutuhan kedalam sebuah software, lalu diimplementasikan ke sebuah model (koding), kemudian testing, diimplementasikan terhadap system yang berjalan, dan yang terakhir evaluasi dan pemeliharaan kedepannya. (A. Budiyantara et al., 2019).

Berikut adalah penjelasan dari SDLC dengan metode waterfall yang penulis jabarkan pada gambar 1. sebagai berikut.

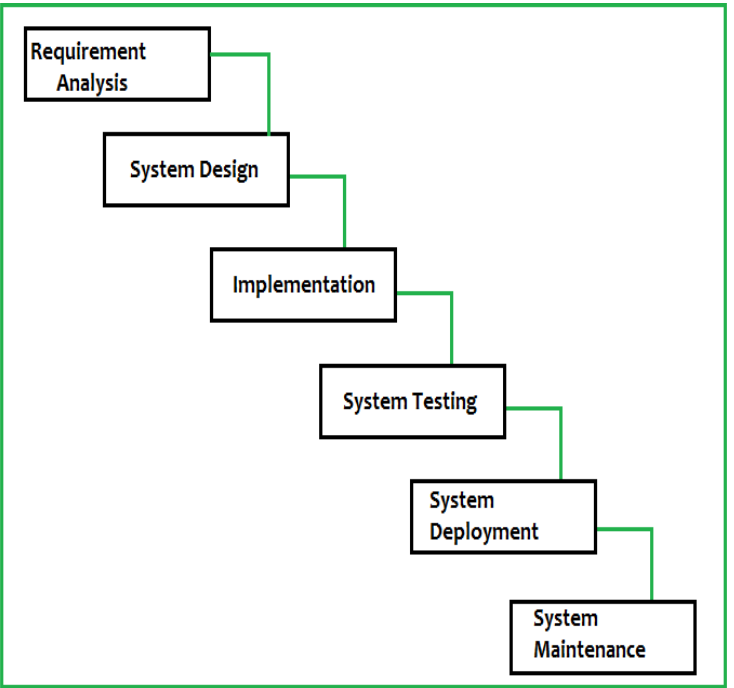

(Sumber : www.bagyatech.com)

Gambar 1. SDLC Waterfall Model

Metode ini digunakan untuk melihat hasil akhir kesesuaian antara software yang penulis rancang dengan desain rancangan. Dan untuk metode yang penulis gunakan adalah metode "Black Box Testing". Dimana metode "Black Box Testing" adalah pengujian yang dilakukan hanya mengamati hasil eksekusi melalui data uji dan memeriksa fungsional dari software yang penulis rancang (Alfaris et al., 2013).

\section{HASIL DAN PEMBAHASAN}

Sistem yang akan dibangun memanfaatkan sistem pendukung keputusan dalam menentukan suatu hasil akhir dan keputusan dalam menentukan pemilihan "Best Agent", karena sistem pendukung keputusan dapat menyelesaikan masalah dengan kriteria-kriteria yang ada. Dalam sistem dilakukan proses perhitungan dengan metode Profile Matching yang meliputi :

1. Analisa subsistem manajemen data.

Tahapan ini digunakan untuk mengidentifikasi variabel dan pembuatan ERD.

2. Analisa subsistem model (Profile Matching)

Membuat analisa terhadap model profile matching yang diterapkan dalam kasus penentuan "Best Agent". Berisi tentang perumusan dan penjabaran hasil dengan metode tersebut.

3. Analisa subsitem dialog

Menganalisa struktur menu sistem dengan bantuan use case diagaram dengan menggunakan software StarUml. 


\section{Perhitungan Nilai GAP}

Nilai GAP dapat dirumuskan sebagai berikut :

GAP = Nilai Pegawai - Nilai Standar (Minimum)

Keterangan :

Nilai Pegawai : Nilai perolehan pegawai berdasrkan penilaian atasan

Nilai Standar : Nilai standar yang diterapkan oleh perusahaan

Perhitungan Nilai Faktor Utama Core Factor (NCF) dan Faktor Tambahan / Secondary Factor $(N S F)$

Untuk rumus perhitungan NCF dan NSF adalah sebagai berikut :

$$
\begin{aligned}
& N C F=\frac{\sum N C}{\sum I C} . \\
& N C F=\frac{\sum N S}{\sum I S} .
\end{aligned}
$$

Keterangan :

NCF : Nilai rata-rata Core Factor.

$\sum \mathrm{NC}$ : Jumlah total nilai Core Factor.

¿IC : Jumlah item Core Factor.

NSF : Nilai rata-rata Secondary Factor.

¿NS : Jumlah total nilai Secondary Factor.

$\sum$ IS : Jumlah item Secondary Factor.

Tabel 1. Perhitungan Bobot

\begin{tabular}{cccl}
\hline No. & Selisih & Bobot & \multicolumn{1}{c}{ Keterangan } \\
\hline 1. & 0 & 5 & $\begin{array}{l}\text { Tidak ada selisih (kompetensi } \\
\text { sesuai dengan yang } \\
\text { dibutuhkan) }\end{array}$ \\
\hline 2. & 1 & 4,5 & $\begin{array}{l}\text { Kompetensi individu } \\
\text { kelebihan 1 tingkat/level }\end{array}$ \\
\hline 3. & -1 & 4 & $\begin{array}{l}\text { Kompetensi individu } \\
\text { kekurangan 1 tingkat/level }\end{array}$ \\
\hline 4. & 2 & 3,5 & $\begin{array}{l}\text { Kompetensi individu } \\
\text { kelebihan 2 tingkat/level }\end{array}$ \\
\hline 5. & -2 & 3 & $\begin{array}{l}\text { Kompetensi individu } \\
\text { kekurangan 2 tingkat/level }\end{array}$ \\
\hline 6. & 3 & 2,5 & $\begin{array}{l}\text { Kompetensi individu } \\
\text { kelebihan 3 tingkat/level }\end{array}$ \\
\hline 7. & -3 & 2 & $\begin{array}{l}\text { Kompetensi individu } \\
\text { kekurangan 3 tingkat/level }\end{array}$ \\
\hline
\end{tabular}

Sumber : (B. A. M. A. Budiyantara, 2019)

\section{Perhitungan Nilai Total}

Untuk menghitung nilai total rumusnya adalah sebagai berikut :

$$
\mathbf{N}=(\mathbf{a}) \% \mathbf{N C F}+(\mathbf{b}) \% \mathbf{N S F}
$$

\section{Aspek Kapasitas Intelektual}

$$
\mathrm{N} 1=(60 \% \times \mathrm{NCF})+(40 \% \times \mathrm{NSF})
$$

Tabel 2. Perhitungan Nilai Total Aspek Kapasitas Intelektual

\begin{tabular}{llccc} 
No. & Nama & $\begin{array}{c}\text { Core } \\
\text { Factor } \\
(\boldsymbol{N C F})\end{array}$ & $\begin{array}{c}\text { Secondary } \\
\text { Factor } \\
(\boldsymbol{N S F})\end{array}$ & N1 \\
\hline 1. & Adhy & 4,83 & 4,25 & 4,60 \\
\hline 2. & Agus & 4,17 & 4,50 & 4,30 \\
\hline 3. & Brian & 4,67 & 4,25 & 4,50 \\
\hline 4. & Heny & 4,00 & 4,75 & 4,30 \\
\hline 5. & Ismail & 4,67 & 4,25 & 4,50 \\
\hline 6. & Novi & 5,00 & 4,00 & 4,60 \\
\hline
\end{tabular}

Sumber : (B. A. M. A. Budiyantara, 2019)

Aspek Sikap Kerja

$$
\mathrm{N} 2=(60 \% \times \mathrm{NCF})+(40 \% \times \mathrm{NSF})
$$

Tabel 3. Perhitungan Nilai Total Aspek Sikap Kerja

\begin{tabular}{llccc}
\hline No. & Nama & $\begin{array}{c}\text { Core } \\
\text { Factor } \\
(\boldsymbol{N C F})\end{array}$ & $\begin{array}{c}\text { Secondary } \\
\text { Factor } \\
(\boldsymbol{N S F})\end{array}$ & N2 \\
\hline 1. & Adhy & 4,17 & 4,00 & 4,10 \\
\hline 2. & Agus & 4,50 & 4,50 & 4,50 \\
\hline 3. & Brian & 3,00 & 3,25 & 3,10 \\
\hline 4. & Heny & 4,33 & 4,50 & 4,40 \\
\hline 5. & Ismail & 4,33 & 3,75 & 4,10 \\
\hline 6. & Novi & 4,83 & 3,75 & 4,40 \\
\hline & & & &
\end{tabular}

Sumber : (B. A. M. A. Budiyantara, 2019)

\section{Aspek Perilaku}

$$
\mathrm{N} 3=(60 \% \times \mathrm{NCF})+(40 \% \times \mathrm{NSF})
$$

Tabel 4. Perhitungan Nilai Total Aspek Perilaku

\begin{tabular}{ccccc}
\hline No. & Nama & $\begin{array}{c}\text { Core } \\
\text { Factor } \\
(\text { NCF })\end{array}$ & $\begin{array}{c}\text { Secondary } \\
\text { Factor } \\
(\text { NSF })\end{array}$ & N3 \\
\hline 1. & Adhy & 4,17 & 5,00 & 4,50 \\
\hline 2. & Agus & 3,67 & 3,50 & 3,60 \\
\hline
\end{tabular}




\begin{tabular}{ccccc}
\hline 3. & Brian & 3,00 & 3,25 & 3,10 \\
\hline 4. & Heny & 4,00 & 4,25 & 4,10 \\
\hline 5. & Ismail & 4,33 & 4,50 & 4,40 \\
\hline 6. & Novi & 4,17 & 3,00 & 3,70 \\
\hline
\end{tabular}

Sumber : (B. A. M. A. Budiyantara, 2019)

\section{Aspek Kedisiplinan}

$$
\mathrm{N} 4=(60 \% \times \mathrm{NCF})+(40 \% \times \mathrm{NSF})
$$

Tabel 5. Perhitungan Nilai Total Aspek Kedisiplinan

\begin{tabular}{cccc}
\hline No. Nama & $\begin{array}{c}\text { Core } \\
\text { Factor } \\
(\text { NCF })\end{array}$ & $\begin{array}{c}\text { Secondary } \\
\text { Factor } \\
(\text { NSF })\end{array}$ & N4 \\
\hline
\end{tabular}

\begin{tabular}{lllll}
\hline 1. & Adhy & 4,00 & 5,00 & 4,40 \\
\hline 2. & Agus & 3,50 & 5,00 & 4,10 \\
\hline 3. & Brian & 3,00 & 3,00 & 3,00 \\
\hline 4. & Heny & 5,00 & 5,00 & 5,00 \\
\hline 5. & Ismail & 3,00 & 4,00 & 3,40 \\
\hline 6. & Novi & 4,75 & 3,00 & 4,05 \\
\hline
\end{tabular}

Sumber : (B. A. M. A. Budiyantara, 2019)

\section{Perhitungan Penentuan Rangking}

Untuk menentukan rangking digunakan rumus sebagai berikut :

Rangking $=($ a) $\% \mathbf{N} 1+(b) \% \mathbf{N} 2+(c) \% \mathbf{N} 3+(d) \% \mathbf{N} 4 \ldots(9)$

Tabel 6. Tabel Perhitungan Rangking

\begin{tabular}{|c|c|c|c|c|c|c|}
\hline No. & Nama & $\begin{array}{c}\mathrm{N} 1 \\
(30 \% \mathrm{x} \\
\mathrm{N} 1)\end{array}$ & $\begin{array}{c}\text { N2 } \\
(30 \% x \\
\text { N2) }\end{array}$ & $\begin{array}{c}\text { N3 } \\
(20 \% x \\
\text { N3) }\end{array}$ & $\begin{array}{c}\mathrm{N4} \\
(20 \% \times \mathrm{N} 4)\end{array}$ & $\begin{array}{c}\text { Hasil Akhir } \\
(\mathrm{N} 1+\mathrm{N} 2+\mathrm{N} 3+\mathrm{N} 4)\end{array}$ \\
\hline 1. & Adhy & 1,38 & 1,23 & 0,90 & 0,88 & 4,39 \\
\hline 2. & Agus & 1,29 & 1,35 & 0,72 & 0,82 & 4,18 \\
\hline 3. & Brian & 1,35 & 0,93 & 0,62 & 0,60 & 3,50 \\
\hline 4. & Heny & 1,29 & 1,32 & 0,82 & 1,00 & 4,43 \\
\hline 5. & Ismail & 1,35 & 1,23 & 0,88 & 0,68 & 4,14 \\
\hline 6. & Novi & 1,38 & 1,32 & 0,74 & 0,81 & 4,25 \\
\hline
\end{tabular}

Sumber : (B. A. M. A. Budiyantara, 2019)

Tabel 7. Rangking dan Penentuan "Best Agent"

\begin{tabular}{llcccccc}
\hline No. & Nama & N1 & N2 & N3 & N4 & $\begin{array}{c}\text { Hasil Akhir } \\
\text { (N1+N2+N3+N4) }\end{array}$ & Rangking \\
\hline 1. & Heny & 1,29 & 1,32 & 0,82 & 1,00 & $\mathbf{4 , 4 3}$ & 1 \\
\hline 2. & Adhy & 1,38 & 1,23 & 0,90 & 0,88 & $\mathbf{4 , 3 9}$ & 2 \\
\hline 3. & Novi & 1,38 & 1,32 & 0,74 & 0,81 & $\mathbf{4 , 2 5}$ & 3 \\
\hline 4. & Agus & 1,29 & 1,35 & 0,72 & 0,82 & $\mathbf{4 , 1 8}$ & 4 \\
\hline 5. & Ismail & 1,35 & 1,23 & 0,88 & 0,68 & $\mathbf{4 , 1 4}$ & 5 \\
\hline 6. & Brian & 1,35 & 0,93 & 0,62 & 0,60 & $\mathbf{3 , 5 0}$ & 6 \\
\hline
\end{tabular}

Sumber : (B. A. M. A. Budiyantara, 2019) 


\section{Perancangan Sistem}

Tahap perancangan SPK penentuan karyawan berprestasi merupakan tahapan dalam membuat rincian SPK dari ketiga subsistem (basis data, model, dan komunikasi atau dialog) agar dimengerti oleh pengguna (user).

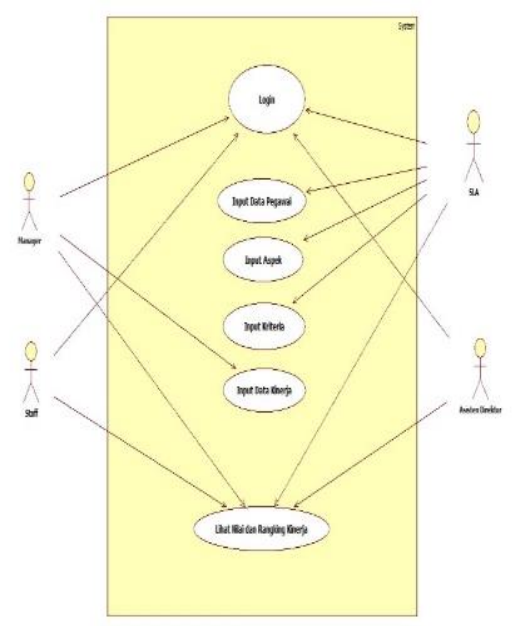

Sumber : (B. A. M. A. Budiyantara, 2019)

Gambar 2. Use case rancangan sistem

Untuk Use Case sistem yang akan dibuat akan melibatkan 4 aktor yaitu Manajer, Asisten Direktur, Staff, dan SLA.

\section{ERD (Entity Relationship Diagram)}

ERD digunakan untuk menggambarkan struktur basis data dan mengidentifikasikan seluruh himpunan entity yang akan terlibat. Didalam system yang dibuat penulis, berikut adalah gambaran rancangan ERD dalam system :

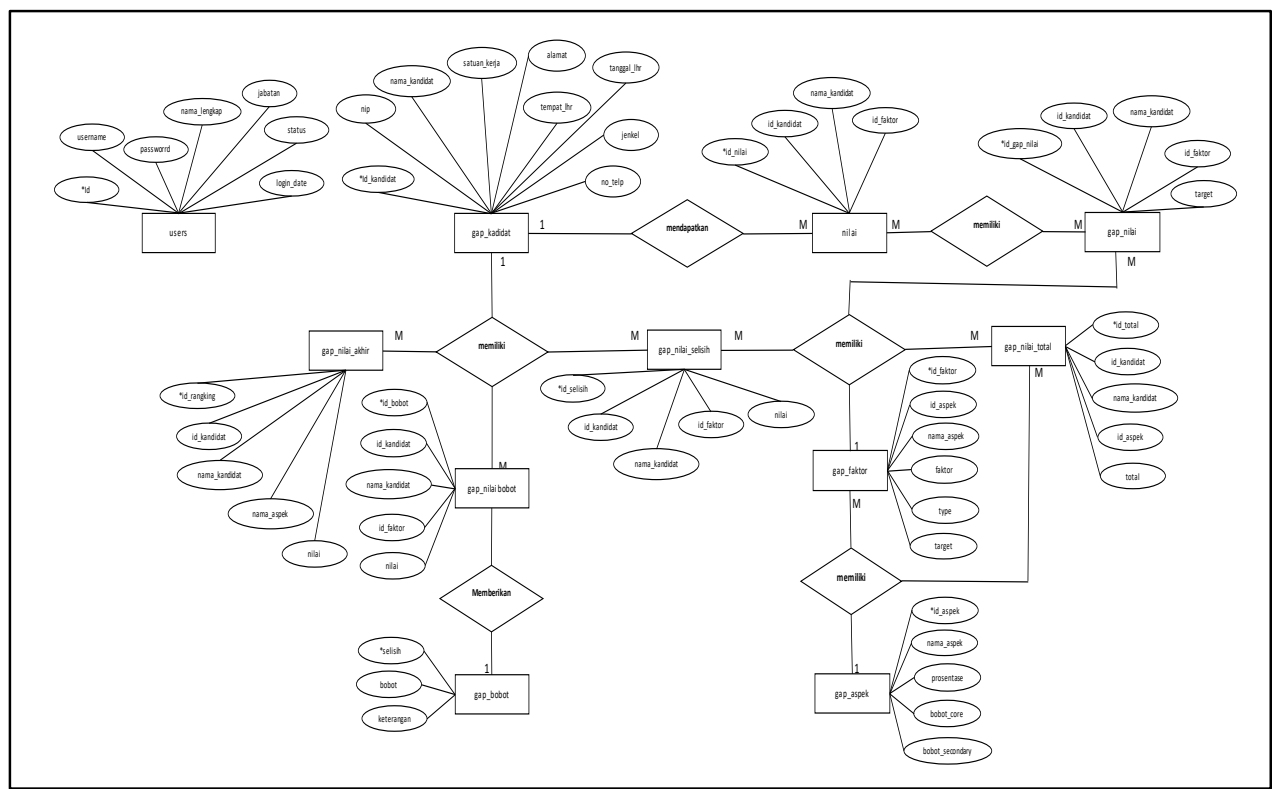

Sumber : (B. A. M. A. Budiyantara, 2019)

Gambar 3. Gambar ERD Sistem 


\section{Tampilan Menu Hasil Penilaian}

Setelah semua terisi, user dapat meilhat langsung hasil penilaian sebagai berikut :

\begin{tabular}{|c|c|c|c|c|c|c|c|c|c|c|c|c|c|c|c|c|c|c|c|}
\hline A Ham & Dma & a & $10 \mathrm{rt}$ & & tse & 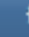 & Sikter & & & & & & & & & & & \multicolumn{2}{|c|}{ Hal, Brian } \\
\hline \multicolumn{20}{|c|}{ Cetak Halaman } \\
\hline \multicolumn{20}{|c|}{ Hasil Nilai } \\
\hline \multirow[b]{2}{*}{ No. } & \multirow{2}{*}{$\begin{array}{l}\text { Nama } \\
\text { Lengkap }\end{array}$} & \multicolumn{5}{|c|}{ Kapasitas Intelektual } & \multicolumn{5}{|c|}{ Slkap Kerja } & \multicolumn{5}{|c|}{ Perilaku } & \multicolumn{3}{|c|}{ Kedisiplinan } \\
\hline & & 1 & 2 & 4 & 5 & 6 & 22 & 23 & 24 & 25 & 26 & 27 & 28 & 29 & 30 & 31 & 32 & 33 & 3 \\
\hline 1 & Adhy & 4 & 3 & 3 & 4 & 2 & 3 & 4 & 1 & 1 & 3 & 2 & 2 & 4 & 3 & 3 & 1 & 3 & \\
\hline 2 & Agus & 2 & 4 & 2 & 3 & 2 & 4 & 2 & 3 & 2 & 3 & 2 & 1 & 2 & 1 & 2 & 1 & 2 & 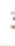 \\
\hline 3 & Brivn & 3 & 2 & 3 & 2 & 4 & 1 & 1 & 1 & 1 & 5 & 1 & 1 & 1 & 1 & 5 & 1 & 1 & \\
\hline 4 & Hery & 2 & 2 & 2 & 3 & 4 & 4 & 4 & 2 & 2 & 3 & 1 & 4 & 4 & 2 & 4 & 3 & 3 & \\
\hline 5 & |smia| & 3 & 2 & 3 & 2 & 4 & 2 & 3 & 2 & 4 & 1 & 3 & 2 & 2 & 3 & 2 & 1 & 1 & ? \\
\hline 6 & Nod & 3 & 3 & 3 & 2 & 2 & 3 & 3 & 4 & 1 & 4 & 3 & 4 & 1 & 1 & 1 & 3 & 4 & \\
\hline $\begin{array}{l}\text { Nill: } \\
\text { Tar }\end{array}$ & I Standar I & 3 & 3 & 3 & 3 & 3 & 3 & 3 & 3 & 3 & 3 & 3 & 3 & 3 & 3 & 3 & 3 & 3 & 3 \\
\hline
\end{tabular}

Sumber : (B. A. M. A. Budiyantara, 2019)

Gambar 4. Tampilan Menu Hasil Penilaian Nilai

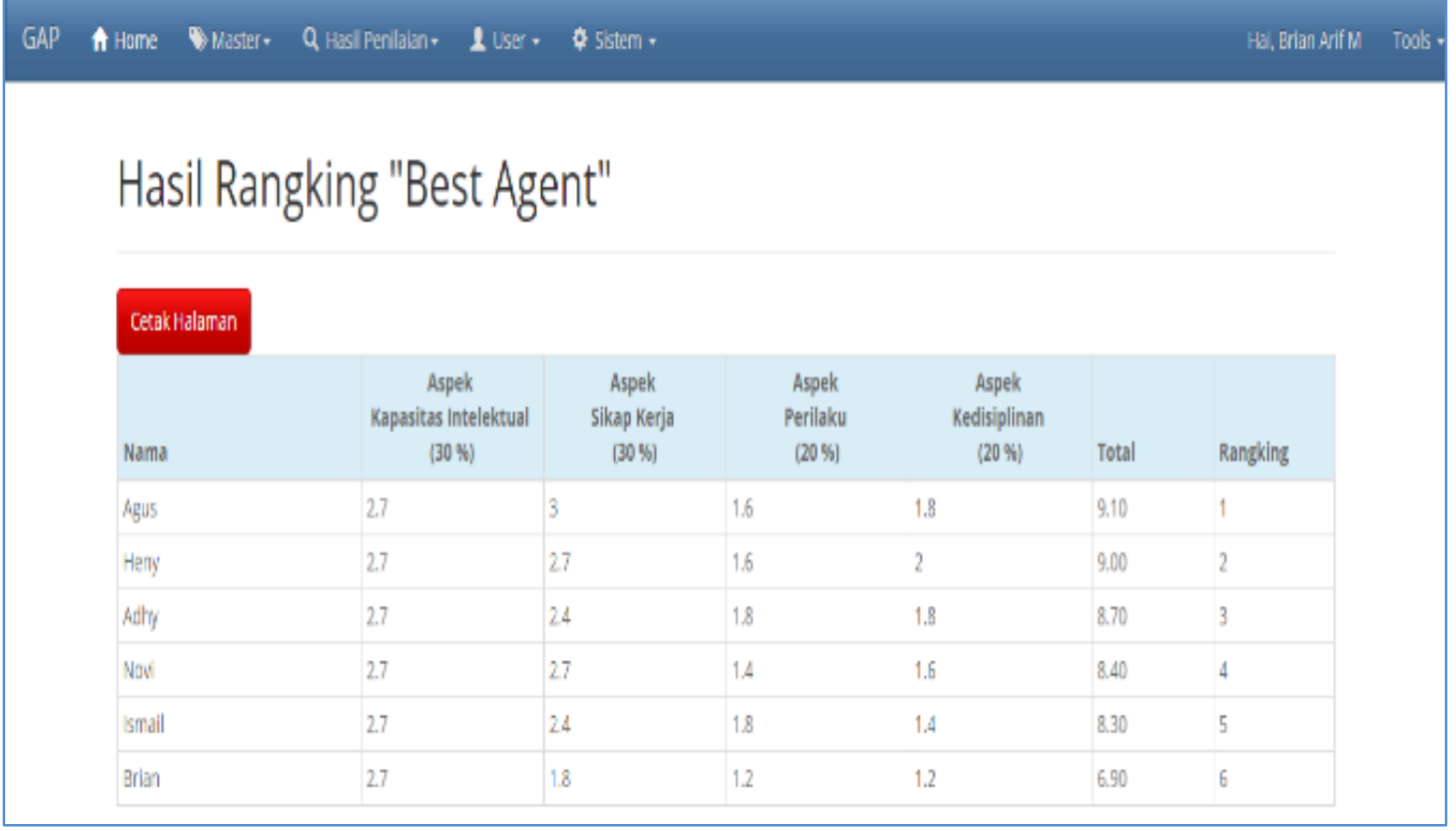

Sumber : (B. A. M. A. Budiyantara, 2019)

Gambar 5. Tampilan Menu Hasil Penilaian Rangking 


\section{KESIMPULAN}

Mempermudah manager dalam pendataan dan penilaian terhadap kinerja staff karena efisiensi waktu dan bisa diakses dimana saja. Dengan sistem ini pengumpulan data penilaian staff oleh manager kemudian bisa langsung diolah oleh Admin (manajer SLA) sehingga mempermudah dan mempercepat pengambilan keputusan akhir. Penyajian sistem pendukung keputusan pemilihan "Best Agent" menggunakan sebuah sistem komputerisasi yang mudah sehingga dapat dilihat oleh penilai (manager) dan juga yang dinilai (staff).

\section{DAFTAR PUSTAKA}

Alfaris, H. B. I., Anam, C., \& Masy'an, A. (2013). Pendaftaran Santri Berbasis Web dengan menggunakan PHP dan MYSQL. SAINTEKBU: Jurnal Sains Dan Teknologi, 6(1), 23-38. http://ejournal.unwaha.ac.id/index.php/saintek/ article/download/64/64/

Apriana, V. (2019). Penerapan Profile Matching Untuk Menentukan. Jurnal Mantik Penusa, 3(1), 15-21.

Budiyantara, A., Studi, P., Informatika, T., Tinggi, S., Informatika, M., \& Mining, D. (2019). Prediksi mahasiswa lulus tepat waktu menggunakan algoritma decision tree (c4.5) pada stmik widuri jakarta. 5(2), 7-13.

Budiyantara, B. A. M. A. (2019). SISTEM PENDUKUNG KEPUTUSAN PEMILIHAN "BEST AGENT" DENGAN METODE PROFILE MATCHING (GAP).

Sani, A. (2016). Analisa Penjualan Retail Dengan Metode Association Rule Untuk Association Rule Untuk Pengambilan Keputusan Strategis Perusahaan : 2(June 2016), 34-50.

Setiawan, A., Andreswari, D., \& Coestera, F. F. (2017). GAP DAN PROFILE MATCHING UNTUK SELEKSI PENERIMAAN PENYIAR RADIO ( Studi Kasus PT Radio Swaraunib FM ). 5(3), 249-259.

Sitanggang, R., \& Sibagariang, S. (2019). Model Pengambilan Keputusan Dengan Teknik Metode Profile Matching. Computer Engineering, Science and System Journal, 4(1), 44. https://doi.org/10.24114/cess.v4i1.11460

Sugiyono. (2013). Metode Penelitian Kuantitatif, Kualitatif, dan $R \& D$. Alfabeta.

Yudi Agusta, P. (2007). K-Means - Penerapan, Permasalahan dan Metode Terkait. Vol. 3, 4760. 
